AperTO - Archivio Istituzionale Open Access dell'Università di Torino

Disability and higher education: assessing students' capabilities in two Italian universities using structured focus group discussions

This is a pre print version of the following article:

Original Citation:

Availability:

This version is available http://hdl.handle.net/2318/1725321

since 2020-01-26T09:49:41Z

Published version:

DOI:10.1080/03075079.2019.1654448

Terms of use:

Open Access

Anyone can freely access the full text of works made available as "Open Access". Works made available under a Creative Commons license can be used according to the terms and conditions of said license. Use of all other works requires consent of the right holder (author or publisher) if not exempted from copyright protection by the applicable law. 


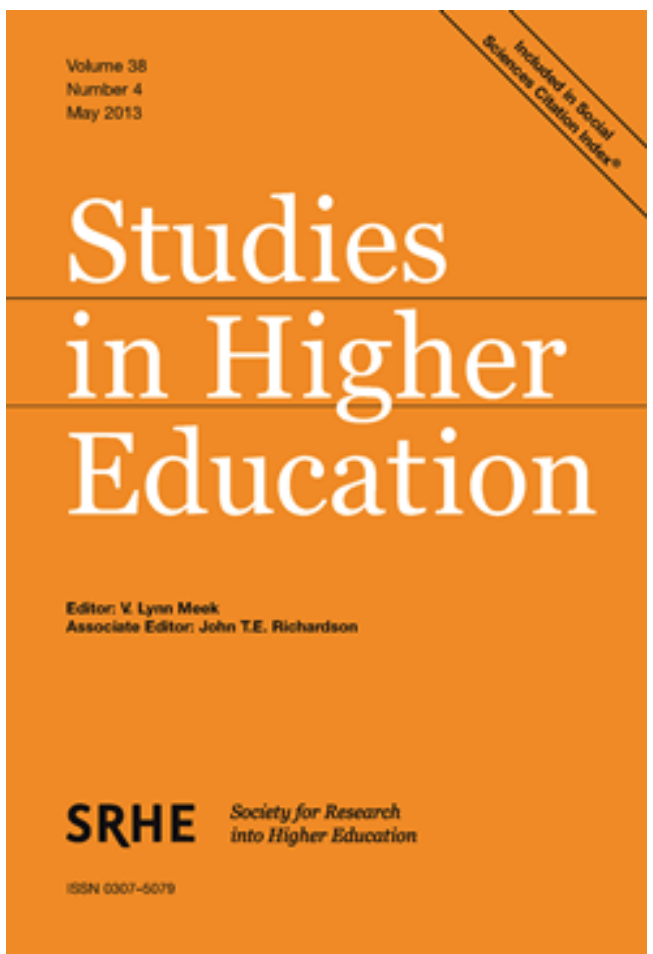

Disability and higher education: assessing students' capabilities in two Italian universities using structured focus group discussions

\begin{tabular}{|r|l|}
\hline Journal: & Studies in Higher Education \\
\hline Manuscript ID & CSHE-2018-0554.R1 \\
\hline Manuscript Type: & Article \\
\hline Keywords: & $\begin{array}{l}\text { University, Disability, inclusion, capability approach, Student } \\
\text { Participation }\end{array}$ \\
\hline \multicolumn{2}{|l}{} \\
\hline
\end{tabular}

\section{SCHOLARONE \\ Manuscripts}




\title{
Disability and higher education: assessing students' capabilities in two Italian universities using structured focus group discussions
}

\begin{abstract}
In the last three decades, inclusive disability legislation has led to an increasing number of students with disabilities entering higher education. However, barriers to the full participation of students remain. This article presents evidence from studies conducted in two Italian universities. Drawing on the Capability Approach, the goal is to analyse the experiences of students with disabilities and to assess their capabilities in academic life. Participatory research methods were adopted using structured focus group discussion techniques. Fifty students with different type of disability participated in the study. Two major findings emerged from the qualitative and quantitative data collected, including: (a) the essential value, in the experience of the students, of being able to use educational spaces, move around outside of the campus and socialize; and (b) low levels of capabilities for students with visual disabilities compared to those with mobility issues, which means that academic inclusion is not for all.
\end{abstract}

Keywords: University, Disability, Capability Approach, Participation

\section{Introduction}

Since the middle of the last century, recommendations from international organisations increasingly promoted the establishment of educational settings that are equal and open to diversity (UNESCO 1994). Regarding individuals with disabilities, the United Nations (UN)' Convention on the Rights of Persons with Disabilities (UN 2006) granted full enjoyment of human rights in all areas of society, including the right to academic inclusion and lifelong learning. This position was reaffirmed in the 2030 Agenda for Sustainable Development, which emphasised the importance of ensuring equal access to all levels of education and vocational training for persons with disabilities by 2030 (UN 2015). Like other European countries, Italy sought to design and implement legislation that focuses on the inclusion of students with disabilities (SWDs) in higher 
education (HE). Law n. 104/92 (Framework law for assistance, social integration, and rights of persons with disabilities) and Law n. 17/99 (Integration and modification of the 5 February 1992 framework law, $n .104$ ) define the legislative framework; in addition, in 2009, Italy ratified the 2006 UN Convention. These intense reforms have encouraged progressive growth in the number of SWDs at universities over the years. Data from the Ministry of Education, University and Research reports that people with disabilities attending post-secondary institutions numbered 26,091 in 2016/17 compared to 4,839 in 2000/01 (the first year in which data is available).

Investment in lifelong learning is thought to significantly affect the quality of life of persons with disabilities. A successful university experience is associated with an increase in capabilities and achievements (Walker 2015) and far-reaching social and economic benefits; for example, data identifies a positive link between HE attendance and the employment rate (ANED 2018; CPS 2017). It follows that education is highly relevant for individuals and society given its intrinsic, instrumental and positional roles in promoting capabilities (Nussbaum 2006; Brighouse and Unterhalter 2008; Authors 2014).

Although the protection of SWDs' right to education in the university has been recognised in many countries and student support services are an important resource in many universities (Fleming, Oertle and Plotner 2017), studies show that people with disabilities still encounter barriers in academic contexts (Moriña 2017). The challenges they face include architectural barriers, despite improvements in physical infrastructure (Collins, Azmat, and Rentschler 2018; Moriña and Morgado 2018). Furthermore, previous research highlights obstacles related to teaching, learning, and assessment, especially when it comes to lectures and classes, coursework and exams (Fuller et al. 2004). Madriaga et al. (2010), who surveys both disabled and non-disabled students, 
suggests the experience of SWD is greater in terms of the amount of time required for coursework, note taking and reading course material (amongst other things). Interestingly, however, many of the challenges that characterise the academic experience of SWDs are also shared by those without impairments (e.g. all participants identified negative sentiments in their engagement with faculty members and teaching practices). More recent studies show that lecturers do not always provide audio recordings of lessons or offer notes or slides prior to a lecture; nor are they always responsive to changing their teaching style or adapting curricula or modes of assessment (Moriña Díez, Gavira López, and Molina 2015; Strnadová, Hájková, and Květoňová 2015; Kendall 2016). Therefore, one form of barrier facing SWDs is the lack of awareness amongst faculty members of their different needs (Redpath et al. 2013; Collins, Azmat, and Rentschler 2018). Literature on faculty attitudes found that lecturers positively endorse inclusive instruction, but do not seem to implement corresponding strategies; in general, they lack confidence in their knowledge of Universal Design for Learning and disability policies (Lombardi, Vukovic, and Sala-Bars 2015; West, Novak, and Mueller 2016). In addition, SWDs seem experience social exclusion because of the negative attitudes of peers and teaching staff or due to avoidance reflecting uncertainty about how to respectfully approach them. Yet, little research has addressed this topic (e.g. Papasotiriou and Windle 2012).

These negative practices disadvantage SWDs. Their academic careers are characterised by relatively delay or failure to complete degree courses and inferior academic performance (Sachs and Schreuer 2011; Kilpatrick et al. 2017). In contrast, a study conducted by Richardson (2009) analysed disability as a predictor of academic success among students earning their first degree and found that "disablement per se does 
not play a significant role in predicting whether an individual student obtains a good degree [defined as a first-class or upper second-class honours degree]" (134).

To our knowledge, few studies have investigated the experiences of SWDs in the Italian context while considering their perspective ${ }^{1}$. Unlike the literature on school education, Italian research focusing on HE is largely unrecognized at the international level.

This paper has two aims. The first is to operationalize the Capability Approach (CA) through participatory methods, i.e. structured focus group discussions (SFGDs), in the HE context. The second is to assess the capabilities of SWDs by applying the SFGDs in two Italian university: Padua and Turin.

The remainder of this paper is structured as follows. First, the relevance of the CA for understanding the experiences of SWDs in university settings is considered. The second and third sections present the research methodology and set out the research questions. And the fourth and fifth sections consider the data and analyse the results.

\section{Theoretical framework and methodology: the Capability Approach and disability}

Most existing studies on inclusive practices in HE institutions have approached this topic using a social model of disability (e.g. Moriña Díez, Gavira López, and Molina 2015; Collins, Azmat, and Rentschler 2018). According to this perspective, society restricts participation in the economic and social spheres of people with disabilities (Oliver and Barnes 2010). This approach suggests that in the academic context, disadvantage and social exclusion experienced by SWDs are the results of attitudinal and environmental barriers.

\footnotetext{
${ }^{1}$ One exception is CENSIS 2017, but this is only a quantitative study.
} 
Drawing on this perspective, we use an approach that usefully complements the social model to explore disability in HE. In doing so, we build on the CA developed by Amartya Sen $(1992,1999)$ and Martha Nussbaum (2000) in an effort to explore the voices and aspirations of SWDs (Hart, 2013).

Our model stresses the achievable functionings (or potential capabilities) that people have reason to value. The capability approach supports an agency-oriented view that emphasizes the relevance of people's ability to live the life they value (Sen 1999) and to influence their own lives as well as those of others (Sen 1992). Within the CA, the SWD capability set (achievable functionings or opportunities to function) is determined by individual conversion factors (including age, gender and type and level of impairment) and their interaction with the social and environmental conversion factors linked to education systems and the specific institution and context (Terzi 2005). The CA considers how individual factors such as wheelchair use interact with the design of the environment the person lives in and the person's valuable ends (Terzi 2011). In other words, disability is a deprivation of capabilities resulting "from the interaction of an individual's (a) personal characteristics (e.g. age, impairment) and (b) basket of available goods (assets, income) and (c) environment (social, economic, political, cultural)" (Mitra 2006, 237). Consequently, the CA focuses on disability as one variable of human diversity and highlights its impact on people within institutional and social settings (Reindal 2009). This new perspective can enrich the social model and its recent integration with the right based approach found in the 2006 UN Convention (Author 2011; Trani et al. 2011).

In (higher) education, disentangling the CA process enables us to identify which factors - given individual, social and environmental conversion factors and their interactions with institutions, resources and services - reduce the opportunities of people with disabilities to exercise valuable beings and doings. For these reasons, this research 
focuses on the nature of impairments and their impact on academic experiences, in line with the findings of other studies that recognise "it is, perhaps, erroneous to talk of disabled students as though they were a single population" (Fuller, 2004, 315). The CA can give university students - with their values, skills, and aspirations - a central role in the process of analysing education systems, because it is centred on the students themselves and their capabilities.

From a broader perspective, the CA is able to embrace the complexity of various phenomena related to HE (McLean and Walker 2012; Boni and Gasper 2012; East, Stokes, and Walker 2014). For example, it promotes new criteria (such as agency, wellbeing, participation, empowerment, equity, diversity, and inclusion), based on key values of human development, for assessing university activities and better orienting a university towards social justice (Boni and Gasper 2012). Moreover, unlike the human capital perspective - which sees education as just an instrument for increasing economic growth (Sen 1999) - the CA and human development perspective views HE as a public good that promotes flourishing lives (Boni and Walker 2013). In the CA, the inclusion of people with disabilities in universities is crucial, because it enables the development of capabilities to fulfil SWDs aspirations and promote agency and tools that are fundamental for active citizenship (Halvorsen et al. 2018). In this way, universities can become concrete “conversion factors" in the students' life projects (Author 2012).

A range of participatory methods can be used to make the CA operational (Author 2019); in this paper, we examine the opinions of SWDs through SFGDs. This method has been selected for its flexibility and is considered in the following section.

\section{Methodological approach: the structured focus group discussion}

The Structured Focus Group Discussion, introduced by Author (2014) within Opportunity-Gap (O-GAP) Analysis, has been used by several authors to operationalise 
the CA in different areas, such as quality of life assessment, disability and rehabilitation, health barriers assessment and project evaluation (see, for example, Author 2018).

This particular participatory method is flexible and enables a general and direct evaluation of individual functionings (outcomes) and capabilities (achievable functionings) within a system such as education, collecting data and information on the capability or real opportunity levels of SWDs as well as capturing obstacles and identifying enabling factors. At the same time, this method provides researchers, participants and policy-makers with useful information for planning and evaluating the impact of certain policies, initiatives or acts, and for indicating the factors and services that facilitate or inhibit final outcomes within the education system.

The method itself combines the classical setting of a focus group with a matrix scoring system (Catley et al., 2008), but is "structured" through a series of steps involving a sequence of actions and questions that are largely fixed and therefore replicable in a clear and defined way, which permits comparability (Author 2018). The 'fixed' structure of focus groups does not diminish the ability to adapt the elements of analysis (e.g. educational sub-dimensions), the context, the typology of intervention, the characteristics of SWDs and the factors and services that promote disabled students' learning and university life.

The structured discussion takes place in a dialogical, collaborative and explorative way with the aim of creating a "community of inquiry" (Author 2012) in which participants, questioning their own convictions, help to create new knowledge and awareness of their reality. Moreover, participants in such discussions have a propensity for taking responsibility with respect to their positions (Author 2017).

For any operationalisation of the capability approach, it is necessary to select the relevant dimensions of well-being to be utilised in the analysis (Author 2011). This can 
be done using different methods (Author 2019, table 1). Therefore, prior to any SFGD, it is important to carefully select dimensions after a thorough desk-analysis of the context, literature and data collected through questionnaires, in-depth interviews or standard focus groups with key informants. The alternative is to give participants (in this case, the SWDs) the opportunity to directly select the most relevant dimensions for analysis via focus group discussions. ${ }^{2}$ At the end of the process, each element and dimension of the matrix must be clearly defined and shared to ensure validity and reliability for all those who took part in the various SFGDs.

At the beginning of each exercise SFGD, each relevant dimension relating to education is captured and confirmed through a participatory ranking exercise with the students.

The selection of participants is based on the heterogeneity and representativeness of SWDs. This is essential for the internal validity of the tool and external validity of the results. Moreover, the heterogeneity of participant reduces the number of SFGDs needed (Author 2014).

The information and data to fulfil the SFGD matrixes are collected via participatory focus group discussions in which SWDs were asked to express their own view and share their opinions regarding their academic lives. The final scores reflect the outcome of the debate in the focus discussions with SWDs: a dialogical mean value. Although the SFGD is a participatory and qualitative tool, it is possible to quantify and systematise the results of the discussion by devising a scoring method consisting of a sequence of structured questions that can be displayed in a Matrix (Author 2014). This

\footnotetext{
${ }^{2}$ Each dimension can be clarified further through the identification of sub-dimensions and the addition of related elements according to the criteria and the target established by the researchers, while still ensuring the researchers' ability to synthesise the methodology (maximum 10-12 dimensions) with the aim of allowing effective and in-depth debates.
} 
facilitated concretising the methodological procedure to be followed in each focus group session, allowing for comparison.

The matrix in Table 1 assembles the collective answers from debates among the participants of focus group discussions (Acocella 2012) and reduces ambiguities and distortions often attributed to traditional focus groups. The rows of the matrix correspond to the dimensions of analysis or outcomes previously identified, i.e. the functioning or dimensions of well-being. The columns refer to different (ideal) typologies of students and/or policies, target groups or services and initiatives.

These profiles are ideal types and are distinguished according to individual characteristics and identities (individual conversion factors such as disability) that influence the results of actions taken in terms of opportunities and final outcomes. The use of ideal type functions to obtain a partial abstraction from the participants of SFGDs helps avoid selfreferential responses based exclusively on personal experiences - i.e. the 'quasi-impartial spectator argument' (Sen 2006; Author 2014).

Each cell of the matrix thus represents the level of capability for the corresponding ideal type of student (column) and for each sub dimension of inclusiveness in the university courses (row).

Scores are awarded on a scale from a minimum of 1 to a maximum of 10 (where 1 is 'Not at all important' and 10 is 'Very important'). These scales were previously tested (along with other possible scales) among students with similar characteristics to ensure the scale producing the most consistent results and detailed evidence was adopted (Author 2012). During the SFGDs the scoring system was explained to participants and subjected to open debate and scrutiny. The final specification of the score in each matrix cell (i.e. the assessment for each question included in the matrix) is based on collective discussion and group answers by students (rather than on individual answers as in a standard 
individual questionnaire). This gave students the opportunity to debate openly through a public enquiry, open-up to different points of views, and reflect on the results and different types of disability.

The matrix structure adds value to the method in terms of comparing the results across different focus group discussions, as it ensures the same sequence of questions.

\section{[insert table 1]}

The application of this method to our research was based on the active involvement of informed SWDs, who were called upon to collectively discuss and analyse specific contexts, services and situations - particularly with reference to functionings and capabilities relevant for higher education and University accessibility.

\section{Research context and aims}

The research was carried out in two Italian universities, Padua and Turin, which have a long tradition of providing services and accommodations to SWDs (Author 2017).

The Universities of Padua and Turin have similar characteristics: they are both regarded as large institutions in terms of the number of students by the Italian the Ministry for Education, University and Research. During the 2014/2015 academic year, the reference period for the present study, 586 SWDs were enrolled in Turin and 501 were enrolled in Padua. In both cases, the proportion of SWDs in the two institutions was $0.9 \%$, which is roughly the same as in other post-secondary Italian institutions.

The specific research aims were to (1) identify relevant capabilities for SWDs in HE; (2) assess the level of opportunity to function in each of these dimensions; and (3) analyse the role of different factors, resources and barriers that affect opportunities to realise personal and educational aspirations at university.

\section{Data Collection and analysis}


The SFGD method was adapted to the research context and followed eight specific steps (Figure 1):

\section{[insert figure 1]}

Step 1. Researchers conducted a CA oriented literature review to identify dimensions that describe the well-being of SWDs in the university context (Nussbaum 2000; WHO 2001; Walker 2006; Spreafico 2013). The eight dimensions identified were:

(1) Teaching and learning

(2) Mobility inside and outside the campus

(3) Interpersonal relationships (during academic activities and leisure time)

(4) Counselling and career development

(5) Access to information

(6) Respect

(7) Health (also mental and spiritual)

(8) Empowerment (to be an empowered and active agent)

Step 2. The SFGD participants were identified through theoretical sampling. A heterogeneous group was selected in terms of gender, type of disability, department of study and year of study at the university.

A total of 38 SWDs from the University of Turin participated. A further 12 students from the University of Padua took part in the SFGD. In both cases, only students assisted by disabilities services were recruited, as, it was not possible to contact individuals who did not seek the assistance of support services despite having declared a disability at the time of enrolment.

The participants from Turin consisted of 21 women and 17 men; 12 had mobility problems, 11 had mental-behavioural disabilities, 9 had visual disabilities and 6 had 
hearing disabilities. The participants from Padua included 6 men and 6 women; 4 had mobility problems, 2 had visual disabilities, 2 had hearing disabilities, 2 had down syndrome and 2 had multiple disabilities. In terms of field of study, SWDs in our sample were enrolled in the humanities (50\% Turin, 60\% Padua), social sciences (37\% Turin, $30 \%$ Padua) and natural sciences (13\% Turin, 10\% Padua). Students with learning disabilities were not included in the study.

Step 3. In both Universities, three levels of SFGDs were conducted. All of these SFGDs were audio-recorded. During the first, researchers asked SWDs to describe their daily routine at the university and to map out their activities. A list was constructed to gather these activities under specific themes representing the central dimensions of wellbeing.

Step 4 and step 5. The second level focused on ranking dimensions (step 4) and opportunity assessment (step 5). In step 4, students ordered the dimensions from the most to the less relevant to express how valuable each dimension was perceived. Meanwhile, in step 5, the groups of students with the same impairment assessed their opportunity level for each dimension by using a scale from 1 (not important) to 10 (very important).

Step 6. The third and final level of SFGDs focused on evaluating the impact of Disability Services, academic staff and interactions with peers on the ability of SWDs' to participation in HE. SWDs responded to the following question with respect to their interaction with Disability Services, academics and peers: How do they support the opportunity level of a student with a disability? (depending on the type of disability; Table 2). This makes it is possible to analyse their respective contributions - whether positive, negative or non-existent - to the well-being of SWDs.

[insert table 2] 
Step 7. The data collected in steps 4 to 6 are analysed. Numerical scores make it possible to quantify the analysis and are useful for comparability synthetic outcomes of two universities.

Step 8. Investigating narratives from which the scores are derived is core to the analysis; it produced qualitative explanations of the processes behind the expansion and contraction of participants' capabilities and opened up space for dialogue between SWDs. It was vital and instructive to collect detailed information on the mechanisms that support capabilities which involved taking extensive notes and comparing any differences of opinion amongst students.

In this study, quantitative scores in opportunity levels have been used directly, without any statistical tests, to compare different disability groups in both universities.

Transcribed focus group discussions were imported into the qualitative analysis program N-Vivo 10, and were analysed using thematic analysis (Braun \& Clarke, 2006).

\section{Results}

The first set of results relate to the co-construction of a situated and contextualised list of dimensions of well-being for SWDs (Table 3).

\section{[insert table 3]}

Several differences emerge if the lists compiled from scientific literature are compared with the lists generated by SWDs:

(1) the dimensions increase from 8 to 9 ;

(2) SWDs did not indicate that empowerment is an important dimension nor did they mention health;

(3) SWDs flag the importance of a new dimension: 'the usability of spaces' (spaces with adequate furniture and technologies) for moving around and working; 
(4) SWDs separated the teaching (didactic) dimension from the learning dimension;

(5) SWDs reformulated the dimension of interior and exterior mobility to include two different concepts: "accessibility" to indicate movement within the university and "mobility" to show mobility outside the university.

The analysis of student responses also reveals the importance of new dimensions for success in the academic life. For many participants 'usability' is a priority for example. One noted:

All libraries should have a location accessible with speech synthesis, even to scan. Why do we have to go to Disability Service? In other libraries there are computers, but we cannot use them because they don't have the right programs (student with visual impairment, Turin) ${ }^{3}$

In addition, mobility generally was seen as a significant and necessary condition for participation within the university:

I meet more hostility with the buses than inside the University. In addition to talking about inclusion in the university, it is necessary to consider the difficulties to get there (student with mobility impairment, Turin)

An interesting result also emerged in the ranking of the dimensions. Students regarded the most important dimension as teaching, while the second most important dimension depended on the nature of their disability. For students with mobility impairments, it was accessibility, while those with visual impairments indicated mobility, those with hearing impairments indicated learning and those with cognitive/mental impairments (other disabilities in Padua) indicated access to information.

Meanwhile, levels of opportunity varied according to university attended and type of disability. The radar graphs presented in Figures 2 and 3 represent the opportunity level assessed by the students with the same impairment attending the same university for each

${ }^{3}$ The quotes employed in this article have been selected to illustrate the analysis and do not constitute a complete evidence base. 
dimension. The results point to "dialogical mean values" of the opportunity levels expressed during step 5 . The area delineated by the dotted lines shows the levels of opportunity in the various dimensions or capability set available to SWDs in academic contexts.

\section{[insert figure 2]}

The data reveals that the University of Turin (Figure 2) provides opportunities to further participation for students with some types of disabilities, while for other disabilities (especially for students with visual impairment), it has not yet fully succeeded in implementing strategies that enable their participation. Teaching, learning and respect are generally evaluated positively by all SWDs, others like guidance and mobility did not always receive positive scores.

In line with the quantitative data, most of the participants discussed positive experiences with their lecturers (in the learning dimension). Faculty members seem willing to offer alternative methods of assessment, especially if the students advise them of their difficulties:

I need extra time. It is difficult to find the right solution in these things, but I spoke with my lecturer and everything went smoothly (student with mental-behavioural disability, Turin)

During lessons (the teaching dimension), the support of a personal tutor came up repeatedly in the SFGDs:

The teachers are helpful. They ask if there is a need for any adaptations, for example regarding the use of videos with subtitles, but then it is difficult for they to consider them. For me, to get to class without the tutor had become a waste of time (student with hearing impairment, Turin)

Typically, participants reported an atmosphere of tolerance and respect:

If we consider the absence of discrimination and marginalization, the judgment in the dimension of respect is very good (student with mobility impairment, Turin) 
On the other hand, some participants expressed concerns about travelling in the city. A student described specific difficulties with mobility:

Around the university there is no tactile paving even to pay it, not even at the stops near the University, perhaps only in one. Yet at the stop where all the buses arrive, there is nothing (student with visual impairment, Turin)

For the University of Padua (Figure 3), the data refers exclusively to mobility and visual impairment. Differences are observed in the students' dimensions of well-being, especially regarding respect and socialisation. Students with mobility impairments perceived the University as more respectful than students with visual impairments. The "dialogical value" of the opportunity levels expressed by the first group is 8 while for the second group it is 5 .

In high school I was isolated and bullied. Now I feel positively about university inclusion. I have found new friends who meet in class (student with mobility impairment, Padua)

Teaching and learning dimensions also received positive evaluations. The University of Padova organizes a General Course for an Inclusive University open to teachers and administrative staff every year.

I went to speak with the professor. I explained my problems, and we agreed upon an oral exam (student with mobility impairment, Padua)

Furthermore, Disability Service offers a peer tutoring service to assist the students throughout the learning process. This support is seen as a necessary condition for coping with lessons:

The tutor helps me in classroom; he takes notes and we study together (student with mobility impairment, Padua)

SWDs remain critical of the mobility situation. For example, a student reported: The mobility service doesn't exist in my town. Even taking the train is complicated. Very often my grandparents bring me to the university (student with visual impairment, Padua)

[insert figure 3] 
The available data makes it possible to compare the two universities in terms of the levels of opportunity indicated by students with mobility problems (Figure 4) and visual disabilities (Figure 5).

[insert figure 4]

[insert figure 5]

Both universities reveal the capacity to remove obstacles to students' participation. If we look at this process from the perspective of students with mobility impairments, we find the same opportunities for participation in both contexts, with a fairly positive evaluation of nearly all dimensions of well-being. If we look at it from the perspective of students with visual disabilities, the opportunities vary according to academic context. The University of Turin seems to be more sensitive to diversity and relationships: socialisation and respect (dialogical mean for both dimensions=7). In contrast, Padua is better placed to facilitate dimensions like teaching, learning and accessibility (dialogical mean for each dimension=7).

Despite the efforts in offering different type of provisions, for the students with visual disabilities some dimensions remain problematic, especially with respect to their aspirations to move and study independently. The participants again emphasize, for example, the difficulties derived from little or no signposting in Braille, as well as the lack of tactile-plantar paths within the university (the accessibility dimension):

I would give a very low rating; if you are blind, everything is inaccessible here. There is no indication in Braille; therefore, you must necessarily request the accompanying service (student with visual impairment, Turin)

Students also pointed to the lack of specific teaching adaptations:

The teachers have always been available; of course, they should better explain graphs and formulas, otherwise a personal tutor is necessary (student with visual impairment, Turin)

Other participants added that developing a sense of belonging is more challenging: 
No lack of respect, but it is as if we were living in two completely separate worlds (student with visual impairment, Padua).

\section{Discussion}

Personal experiences allow students to reformulate their participation in HE articulated in nine dimensions. The list generated by the students emphasises the importance of interior and exterior mobility ("accessibility" within the university and "mobility" outside the university), adds a new dimension to lists advocated in the literature (the "usability" of spaces), and confirms that socialisation and respect are among the most important dimensions for students.

For SWDs, accessibility by itself is not enough. Just because a space is architecturally accessible does not mean that it is usable: having a suitable space, one that is large enough and equipped with the technology necessary for studying is vital for ensuring that SWDs can participate in university life.

If we then examine the ranking of the importance attached to dimensions and the levels of opportunity, we see that these differ in both universities depending on the nature of the disability and the dimensions considered. The situation is very different if we analyse the levels of opportunity for students with mobility disabilities in the two universities and compare them to levels of opportunity for students with visual disabilities.

If socialisation is excluded, the levels of opportunity for students with mobility impairments are roughly the same in the two universities, as opposed to the levels of opportunity indicated by students with visual disabilities, who hold very different perceptions. This difference may reflect the efforts that the two universities have made in facilitating the participation of students with mobility impairments, a disability for which, 
thanks to the involvement of associations campaigning for people with disabilities (Shakespeare 2014), there has been a more inclusive attitude towards for some time.

However, for students with visual disabilities, participation appears to depend heavily on the context in which they study and live. For a student with a visual disability, choosing to study in Padua or Turin results in different capabilities to function in virtually all dimensions; this means that uneven practices continue to occur between academic staff, departments and institutions (Tinklin and Hall 1999; Holloway 2001).

Nevertheless, one aspect experienced in both universities concerns the fact that the mobility dimension - or rather, the obstacles that SWDs encounter in travelling to and from university (while subject to some variation) - is among the most critical factors that hampers participation. More emphasis needs to be placed on tailored services that facilitate personal mobility if equal participation in broader aspects of university life is to be ensured for SWDs. Furthermore, specific issues arise for students with visual disabilities. The lack of tactile paving at bus stops and train stations and the lack of academic information in Braille greatly reduce mobility opportunities and create dependence, which undermines personal autonomy and other goals. Previous studies tend to focus on the architectural barriers within institutions (e.g. Holloway 2001; Redpath et al. 2013). Just recently, research has investigated the problems SWDs face in trying to reach academic institutions (Moriña and Morgado 2018), but the specific problem of visual barriers (outside and within the campus) remains poorly documented within the literature (Lourens and Swartz 2016).

The results of the study indicate positive assessments in terms of learning opportunities. Participants reported that their universities were supportive and provided accommodation to meet their needs during exams, in accordance with existing legislation.

In terms of the teaching dimension, the most important form of support for 
students are the tutor provided by Disability Services. The high quantitative score assigned by SWDs in this dimension reflects the tutor support. Students cannot choose whether to use the tutor's support; it is considered essential also because lecturers do not seem to be committed to implementing inclusive practice of teaching. These results describe a little knowledge by lecturers towards providing curricular adaptations similar to those documented in other HE systems (Moriña Díez, Gavira López, and Molina 2015; Kendall 2018), confirming that teaching remains an area of particular concern.

Finally, the fact that the participants did not point to the empowerment dimension or emphasises the importance of physical, mental and spiritual well-being can be interpreted in one of two ways. The first explanation is that they do not value their university experience in terms of well-being or empowerment. In fact, SWDs may not think that their university's is responsible for supporting these functionings. Teaching is the relevant priority, as the rankings suggest. As Soorenian (2014) points out, access to a university degree is fundamental for being able to compete in the employment market. However, when it comes to the empowerment dimension specifically, it is also possible that adapting to academic contexts has reduced the ability of students to perceive university well-being as connected to the fulfilment of their own agency. In fact, studies suggest that university policy-makers have only marginally involved people with disabilities in the creation of the services and institutional policies implemented on their behalf (Luna 2009; Beauchamp-Pryor 2013). The fact that the voices of SWDs have rarely been considered by universities may have affected their aspirations for authentic and meaningful participation in the academic world.

\section{Conclusion}

This study has identified several spaces in which gaps emerge between the lived experiences of students and what they value in HE. First, issues such as socialisation, 
mobility outside of the university and the usability of spaces (traditionally poorly studied), must be better addressed by Disability Services in HE to guarantee equal capabilities and well-being for all students - especially for those with visual impairments. Second, while academic staff seems to make reasonable adjustments for exams, the teaching experience is above all supported by the tutor support. Training all lecturers in disability awareness and the adaptation of their teaching styles to the needs of SWDs is likely to be essential for implementing a universal learning design. Finally, to empower SWDs on the campus, universities should seek feedback from students and encourage them to participate in such initiatives (it is worth recalling that only 12 students from the University of Padua agreed to take part in this research). As Sen (2009: 17) has remarked, "the focus of the CA is not just on what a person actually ends up of doing, but also on what she is capable of doing, whether or not she chooses to make use of that opportunity".

In this respect, the SFGD method is relevant for making the CA operational, as it opens up spaces in which SWDs can exercise their agency by creating a "community of inquiry" (Author 2019). The SFGD method engages students in all phases of the research and encourages them to adopt the positions of quasi-impartial spectators to reduce the risk of relying solely on personal experiences that might tarnish insights. The SFGD helps reduce the ambiguities and distortions attributed to traditional focus groups (Acocella 2012; Author 2014). The comparability of results across different focus group discussions is a key advantage of this matrix structure, which ensures the same sequence of questions. Moreover, SFGDs aid detailed and in-depth analysis of opportunities and barriers, evaluating the capabilities and functionings with quantitative scores and qualitative narratives. It follows that the use of SFGDs could be useful, as this study shows, for obtaining reliable information and data as well as contributing to the empowerment of SWDs. 


\section{Declaration of interest statement}

The authors declared no potential conflicts of interest with respect to the research, authorship and/or publication of this article. 


\section{References}

Acocella, I. 2012. "The focus groups in social research: advantages and disadvantages." Quality \& Quantity 46 (4): 1125-1136.

ANED. 2018. "European comparative data on Europe 2020 \& People with disabilities. " https://www.disability-europe.net/theme/statistical-indicators

Beauchamp-Pryor, K. 2013. Disabled students in Welsh higher education: A framework for equality and inclusion. Sense Publishers: Rotterdam.

Boni, A., and D. Gasper. 2012. "Rethinking the quality of universities: How can human development thinking contribute?." Journal of Human Development and Capabilities 13 (3): 451-470.

Boni, A., and M. Walker. 2013. "Introduction. Human development, capabilities and universities of the twenty-first century." In Universities and Human Development: A New Imaginary for the University of the XXI Century, edited by Alejandra Boni and Melanie Walker, 1-10. London: Routledge.

Braun, V., and V. Clarke. (2006). Using thematic analysis in psychology. Qualitative Research in Psychology, 3 (2): 77-101.

Brighouse, H., and E. Unterhalter. 2008. "Primary Goods versus Capabilities: Considering the Debate in Relation to Equalities of Education". In Capabilities Handlungsbefähigung und Verwirklichungschancen in der Erziehungswissenschaft, edited by H.-U. Otto and H. Zegler, 69-84. Wiesbaden: VS-Verlag.

Catley, A., J. Burns, D. Abebe, and O. Suji. 2008. Participatory Impact Assessment: A Guide for Practitioners, Somerville: Feinstein International Center, Tufts University.

CENSIS. 2017. Accompagnare le università verso una più ampia integrazione degli studenti con disabilità e dsa. Roma: CENSIS. 
Collins, A., F. Azmat, and R. Rentschler. 2018. "'Bringing everyone on the same journey': revisiting inclusion in higher education." Studies in Higher Education: 1-13.

CPS (Current Population Survey) 2017. "Persons with a disability: labor force characteristics.” https://www.bls.gov/news.release/pdf/disabl.pdf

East, L., R. Stokes, and M. Walker. 2014. "Universities, the public good and professional education in the UK." Studies in Higher Education 39 (9): 1617-1633.

Fleming, A. R., Oertle, K. M., and A. J. Plotner. 2017. "Student Voices: Recommendations for Improving Postsecondary Experiences of Students with Disabilities." Journal of Postsecondary Education and Disability, 30(4): 309-326.

Fuller, M., M. Healey, A. Bradley, and T. Hall. 2004. "Barriers to learning: a systematic study of the experience of disabled students in one university." Studies in Higher Education 29 (3): 303-318.

Hart, C S. 2013. Aspirations, Education and Social Justice Applying Sen and Bourdieu. London: Bloomsbury.

Holloway, S. 2001. "The experience of higher education from the perspective of disabled students." Disability \& Society 16 (4): 597-615.

Kendall, L. 2018. "Supporting students with disabilities within a UK university: Lecturer perspectives." Innovations in Education and Teaching International 55(6): 694-703.

Kilpatrick, S., Johns, S., Barnes, R., Fischer, S., McLennan, D., and K. Magnussen. 2017. "Exploring the retention and success of students with disability in Australian higher education." International Journal of Inclusive Education, 21(7): 747-762.

Lombardi, A., Vukovic, B., and I. Sala-Bars. 2015. "International Comparisons of Inclusive Instruction among College Faculty in Spain, Canada, and the United States." Journal of Postsecondary Education and Disability 28(4): 447-460. 
Lourens, H., and L. Swartz. 2016. "Experiences of visually impaired students in higher education: bodily perspectives on inclusive education." Disability \& society, 31(2): $240-251$.

Luna, C. 2009. "But How Can Those Students Make It Here?: Examining the Institutional Discourse about What It Means to Be 'LD' at an Ivy League University." International Journal of Inclusive Education 13(2): 157- 178.

Madriaga, M., K. Hanson, C. Heaton, H. Kay, S. Newitt, and A. Walker. 2010. "Confronting similar challenges? Disabled and non-disabled students' learning and assessment experiences." Studies in Higher Education 35(6): 647-658.

McLean, M., and M. Walker. 2012. "The possibilities for university-based public-good professional education: a case-study from South Africa based on the 'capability approach'." Studies in Higher Education 37 (5): 585-601.

Mitra, S. 2006. "The capability approach and disability." Journal of Disability Policy Studies 16: 236-247.

Moriña, A. 2017. "Inclusive education in higher education: challenges and opportunities." European Journal of Special Needs Education 32 (1): 3-17.

Moriña, A., R. Gavira López and V.M. Molina. 2015. "Students with disabilities in higher education: a biographical-narrative approach to the role of lecturers." Higher Education Research \& Development 34 (1): 147-159. doi: $10.1080 / 07294360.2014 .934329$

Moriña, A., and B. Morgado. 2018. "University surroundings and infrastructures that are accessible and inclusive for all: listening to students with disabilities. " Journal of Further and Higher Education 42 (1): 13-23. 
Nussbaum, M. 2000. Women and human development: The capabilities approach. Cambridge: Cambridge University Press.

Nussbaum, M. 2006. "Education and Democratic Citizenship: Capabilities and Quality Education." Journal of Human Development 7 (3): 385-398.

Oliver, M., and C. Barnes. 2010. "Disability Studies, Disabled People and the Struggle for Inclusion." British Journal of Sociology of Education 31 (5): 547-560. doi:10.1080/ 01425692.2010.500088.

Papasotiriou, M., and J. Windle. 2012. "The social experience of physically disabled Australian university students." Disability \& Society 27 (7): 935-947.

Redpath, J., P. Kearney, P. Nicholl, M. Mulvenna, J. Wallace, and S. Martin. 2013. "A qualitative study of the lived experiences of disabled post-transition students in higher education institutions in Northern Ireland." Studies in Higher Education 38 (9): 13341350.

Reindal, S. M. 2009. "Disability, capability, and special education: towards a capability-based theory." European Journal of Special Needs Education 24 (2):155168. doi: $10.1080 / 08856250902793610$

Richardson, J. T. E. 2009. "The academic attainment of students with disabilities in UK higher education." Studies in Higher Education 34 (2): 123-137.

Sachs, D., and N. Schreuer. 2011. "Inclusion of Students with Disabilities in Higher Education: Performance and participation in student's experiences." Disability Studies Quarterly 31 (2).

Sen, A. 1992. Inequality Re-examined. Oxford and New York: Oxford University Press. Sen, A. 1999. Development as Freedom. New York: Alfred A. Knopf. 
Sen, A. 2006. "What do we want from a theory of justice?." The Journal of Philosophy 103 (5): 215-238.

Sen, A. 2009. The Idea of Justice. London: Allen Lane.

Shakespeare, T. 2014. Disability rights and wrong revisited. London: Routledge.

Soorenian, A. 2014. "How inclusive are the pedagogical practices in British Universities?

" Italian Journal of Disability Studies 2 (2): 13-47.

Spreafico, A.M.C. 2013. "Liberal arts education and the formation of valuable capabilities. " In Human Development and Capabilities. Re-imagining the university of the twenty-first century, edited by Alejandra Boni and Melanie Walker, 129-144. Ney York: Routledge.

Strnadová, I., V. Hájková, and L. Květoňová. 2015. "Voices of university students with disabilities: inclusive education on the tertiary level-a reality or a distant dream?." International Journal of Inclusive Education 19 (10): 1080-1095.

Terzi, L. 2005. "A capability perspective on impairment, disability and special needs. Towards social justice in education." Theory and Research in Education 3: 197-223.

Terzi, L. 2011. "Vagaries of the natural lottery? Human diversity, disability, and justice: A capability perspective." In Disability and disadvantage, edited by Kimberley Brownlee and Adam Cureton, 86-111. Oxford: Oxford University Press.

Tinklin, T., and J. Hall. 1999. "Getting round obstacles: disabled students' experiences in higher education in Scotland." Studies in Higher Education 24 (2): 183-194.

UN. 2006. Convention on the Rights of Persons with Disabilities.

UN. 2015. Transforming our world: the 2030 Agenda for Sustainable Development.

Unesco. 1994. The Salamanca Statement and framework for action on special needs education. Paris: Unesco publishing. 
Walker, M. 2006. Higher education pedagogies: A capabilities approach. Maidenhead: SRHE/Open University Press \& McGraw-Hill.

Walker, M. 2015. "Advancing student well-being and agency: outline of a 'capabilitiesfriendly' approach". South African Journal of Higher Education 29(5): 279-296.

West, E. A., Novak, D., and C. Mueller. 2016. "Inclusive Instructional Practices Used and Their Perceived Importance by Instructors." Journal of Postsecondary Education and Disability 29(4): 363-374.

WHO. 2001. International Classification of Functioning, Disability and Health. 
Figures

Figure 1 Research phases

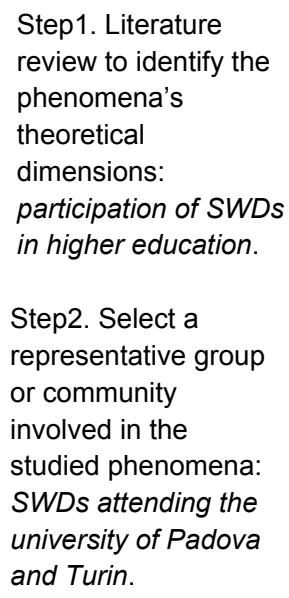

Second level of
$\quad$ SFGD
Step4. Each
participant assesses
the importance of
how each
dimension:
discussion about
ranking

Step5. Each participant assesses his/her actual opportunity level regarding each dimension: discussion about opportunity level of SWDs

$\begin{gathered}\text { Third level of } \\ \text { SFGD }\end{gathered}$
Step6. Each
participant assesses
how the
programme/service
supports his/her
opportunity level:
impact of Disability
Service in promoting
SWDs' participation

Step7. Data analysis:

researchers analyse quantitative and qualitative data collected in step 4 , 5 , and 6

Step8. The group discusses the results: researchers and SWDs discuss the results of SFGD

Figure 2 Levels of opportunity for students with disabilities at the University of Turin $(\mathrm{N}=38)$

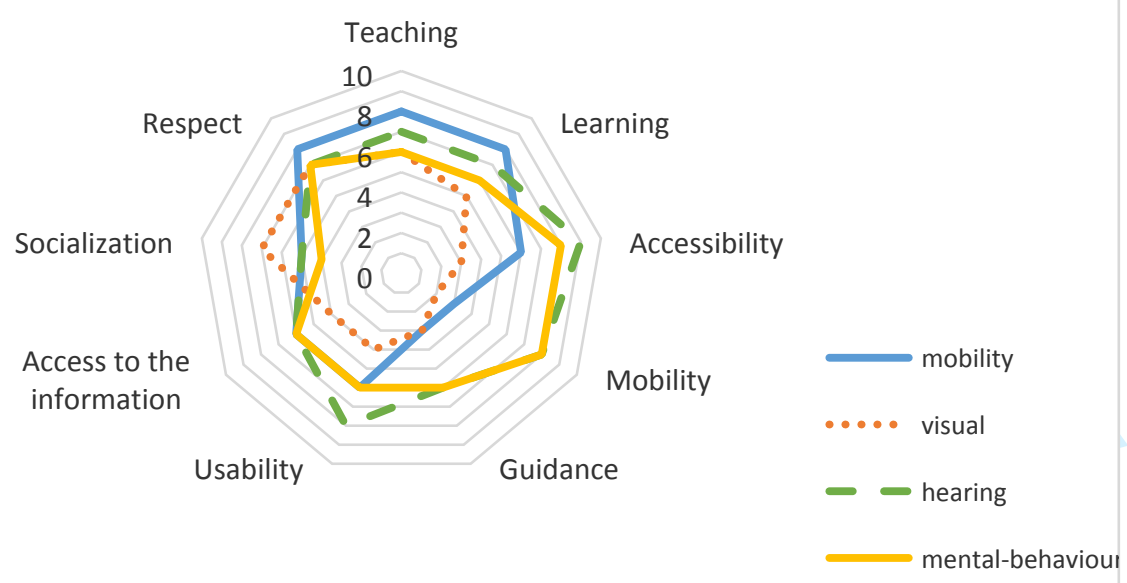


Figure 3 Levels of opportunity for students with disabilities at the University of Padua $(\mathrm{N}=12)$

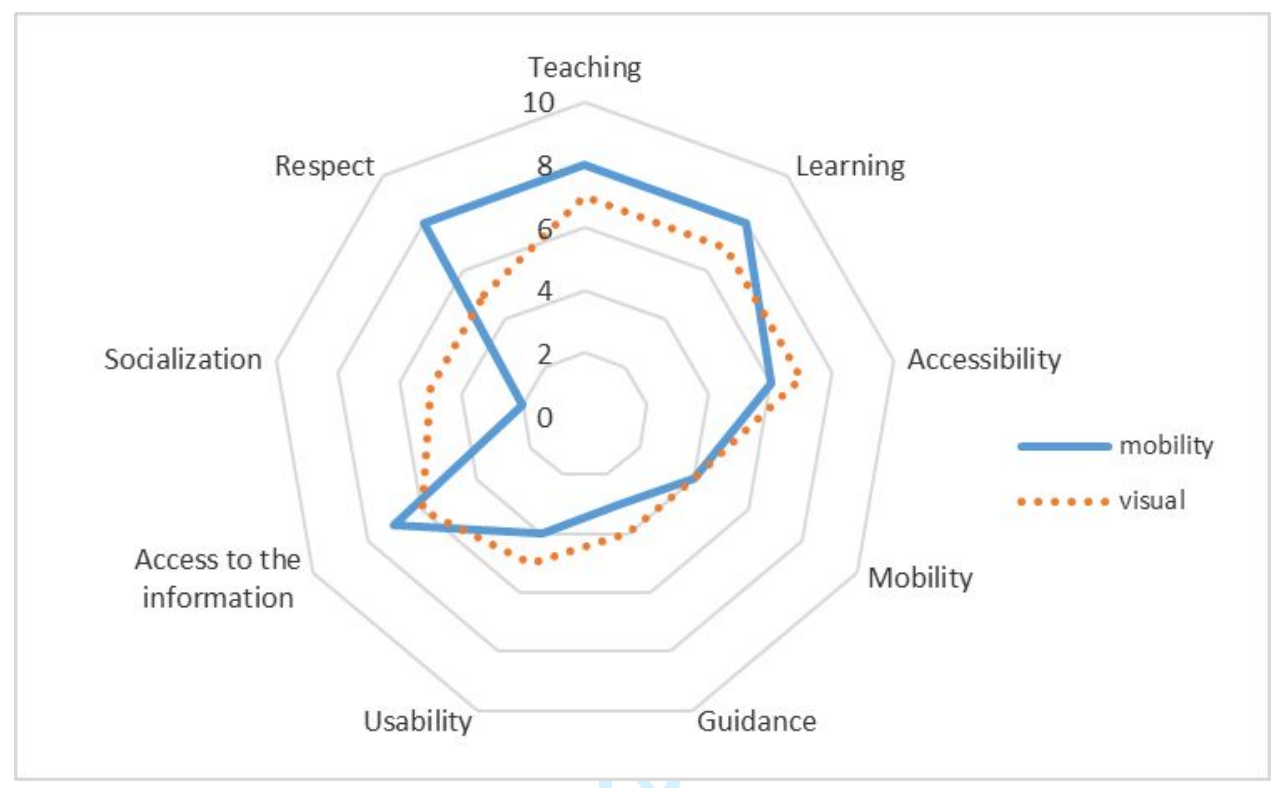

Figure 4 Levels of opportunity for students with mobility disabilities, comparison between the two universities

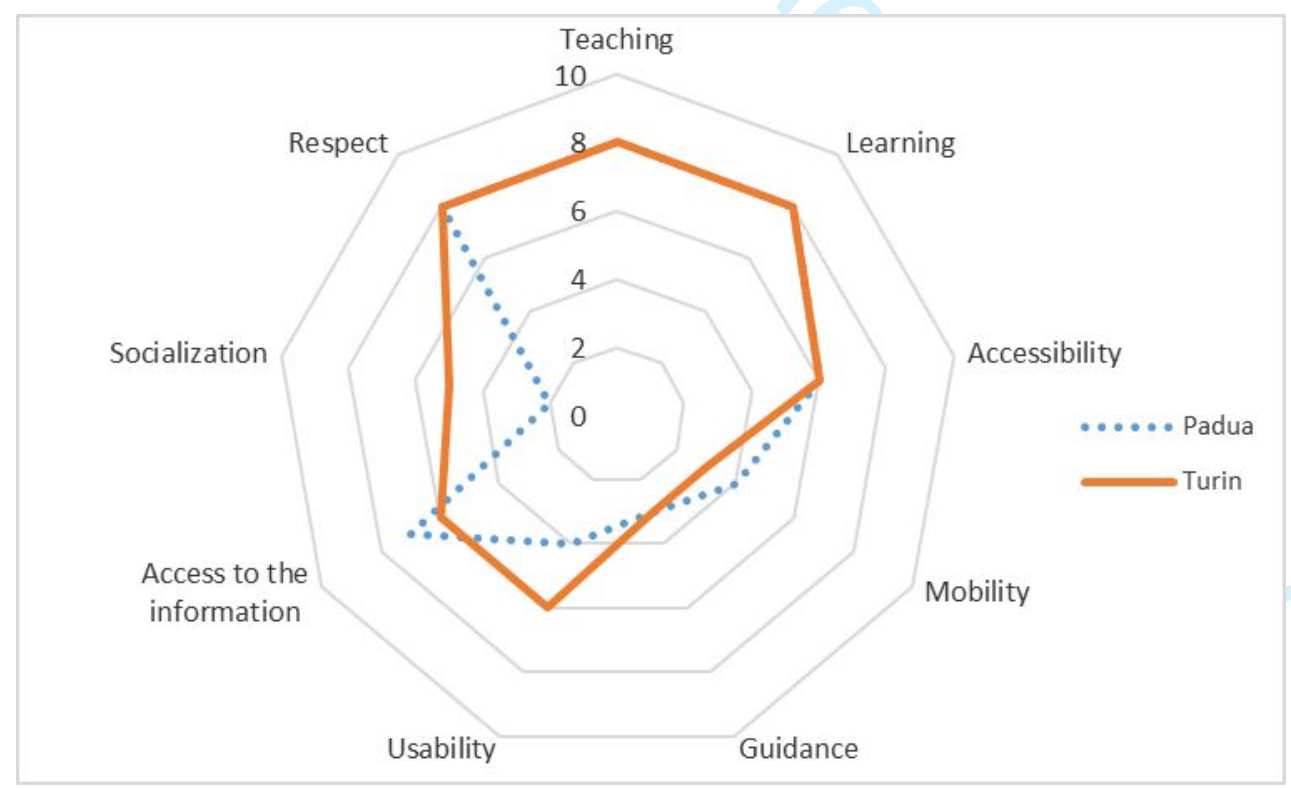


Figure 5 Levels of opportunity for students with visual disabilities, comparison between the two universities

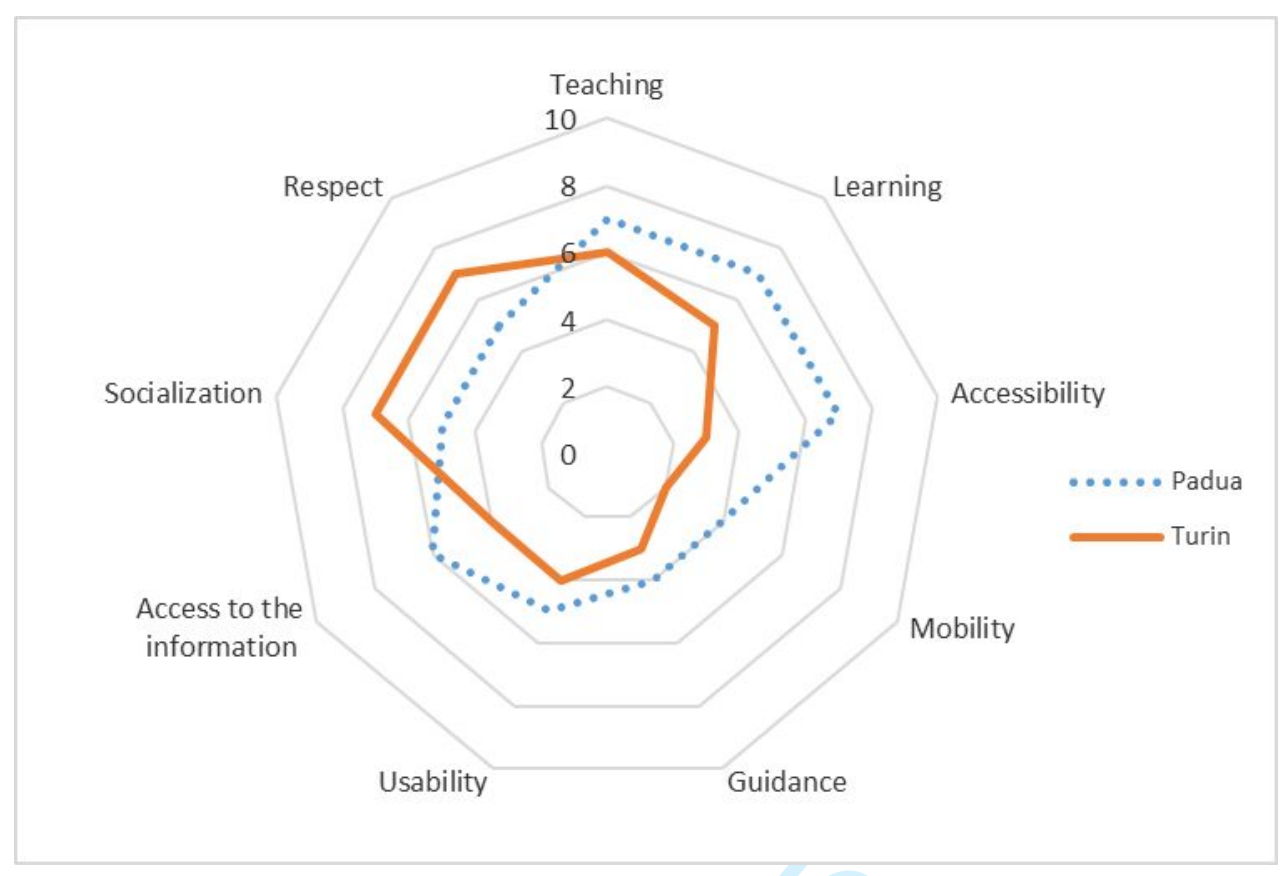


Figure 2 Levels of opportunity for students with disabilities at the University of Turin $(\mathrm{N}=38)$

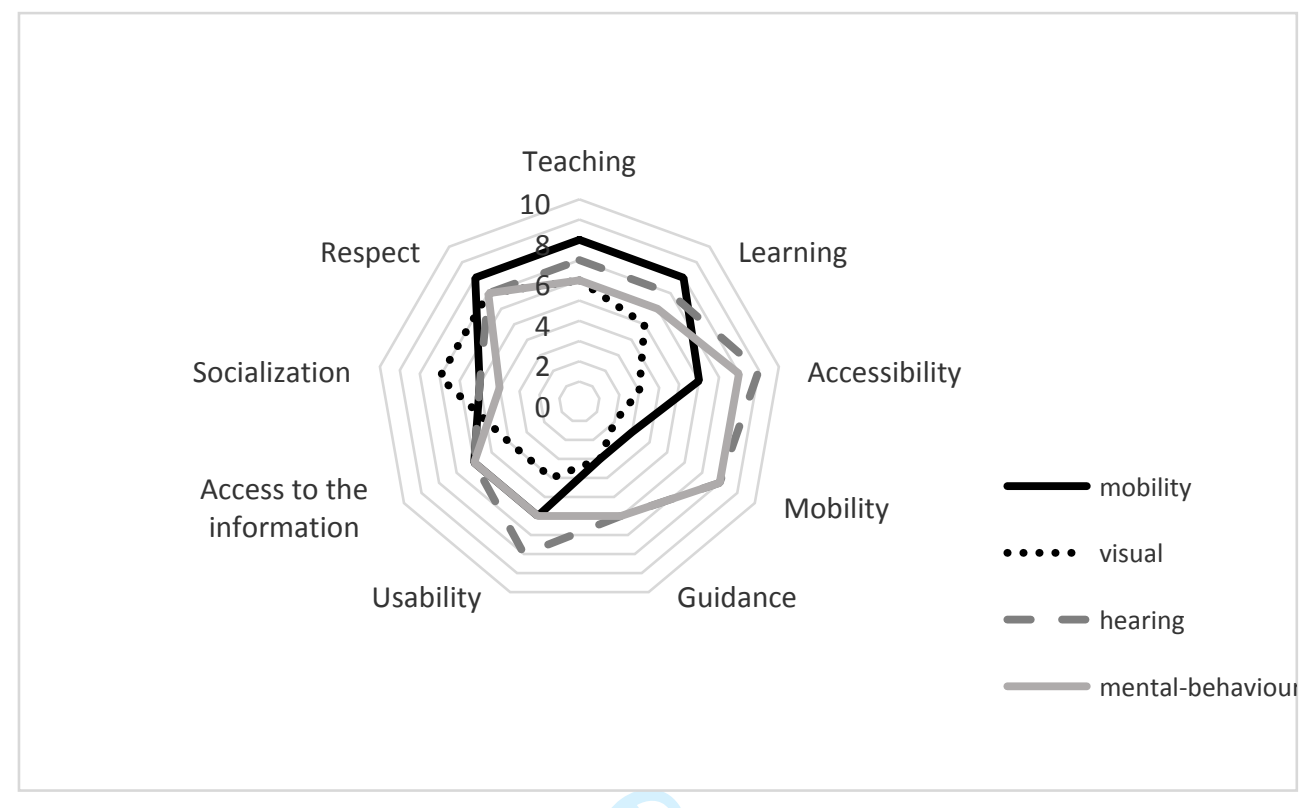

Figure 3 Levels of opportunity for students with disabilities at the University of Padua $(\mathrm{N}=12)$

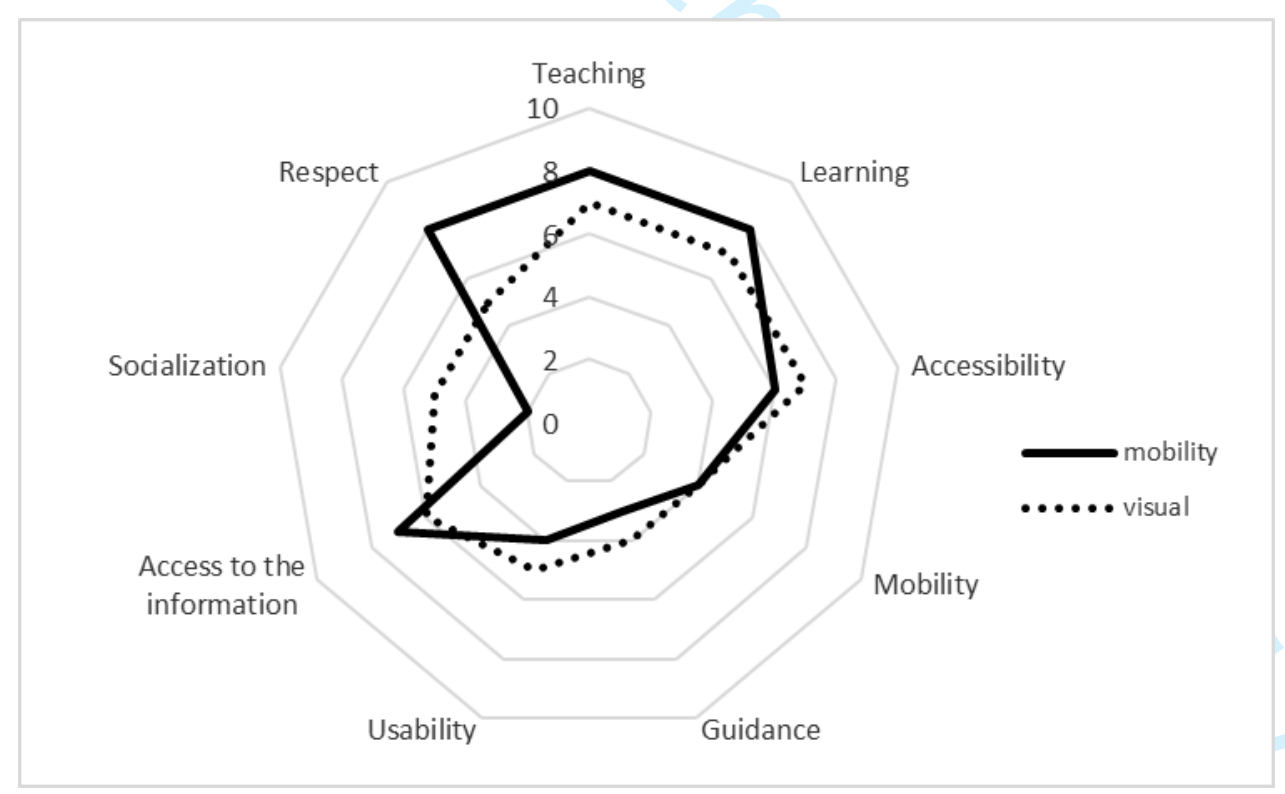


Figure 4 Levels of opportunity for students with mobility disabilities, comparison between the two universities

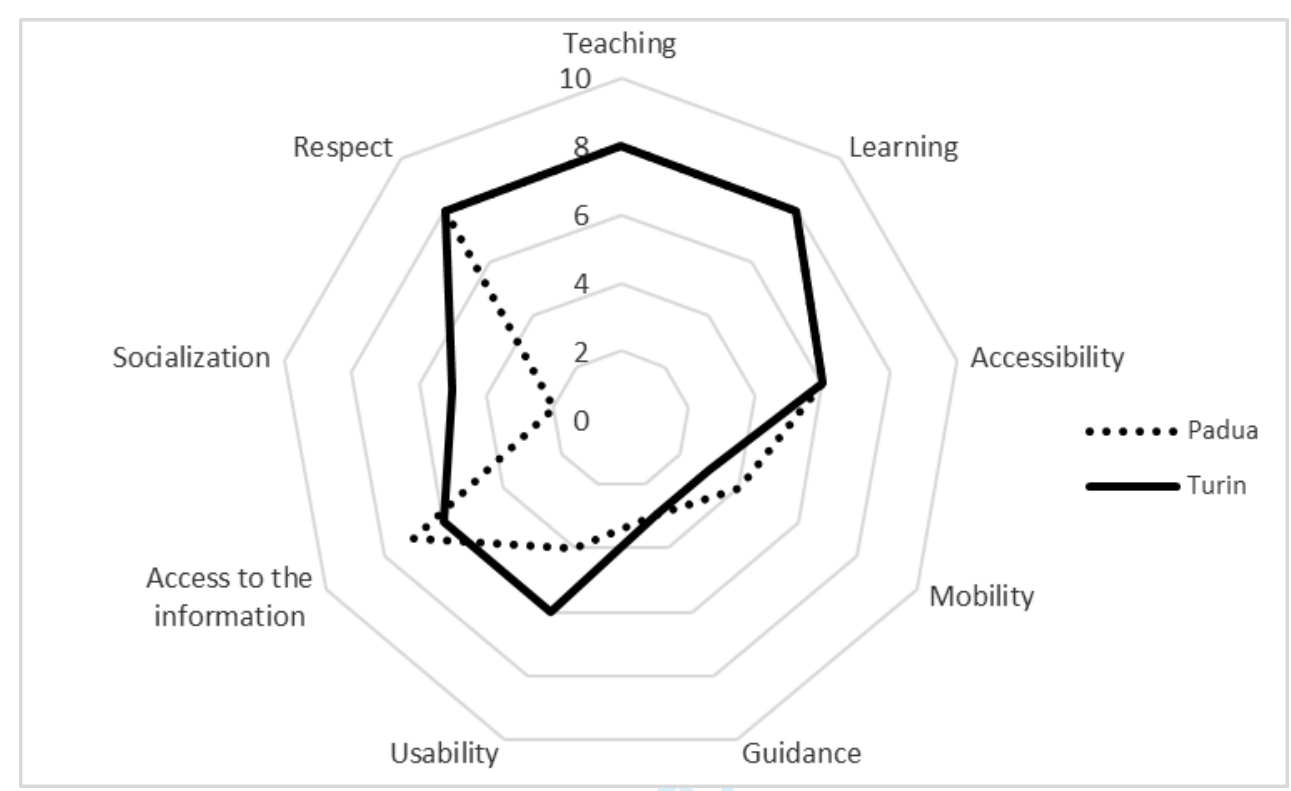

Figure 5 Levels of opportunity for students with visual disabilities, comparison between the two universities

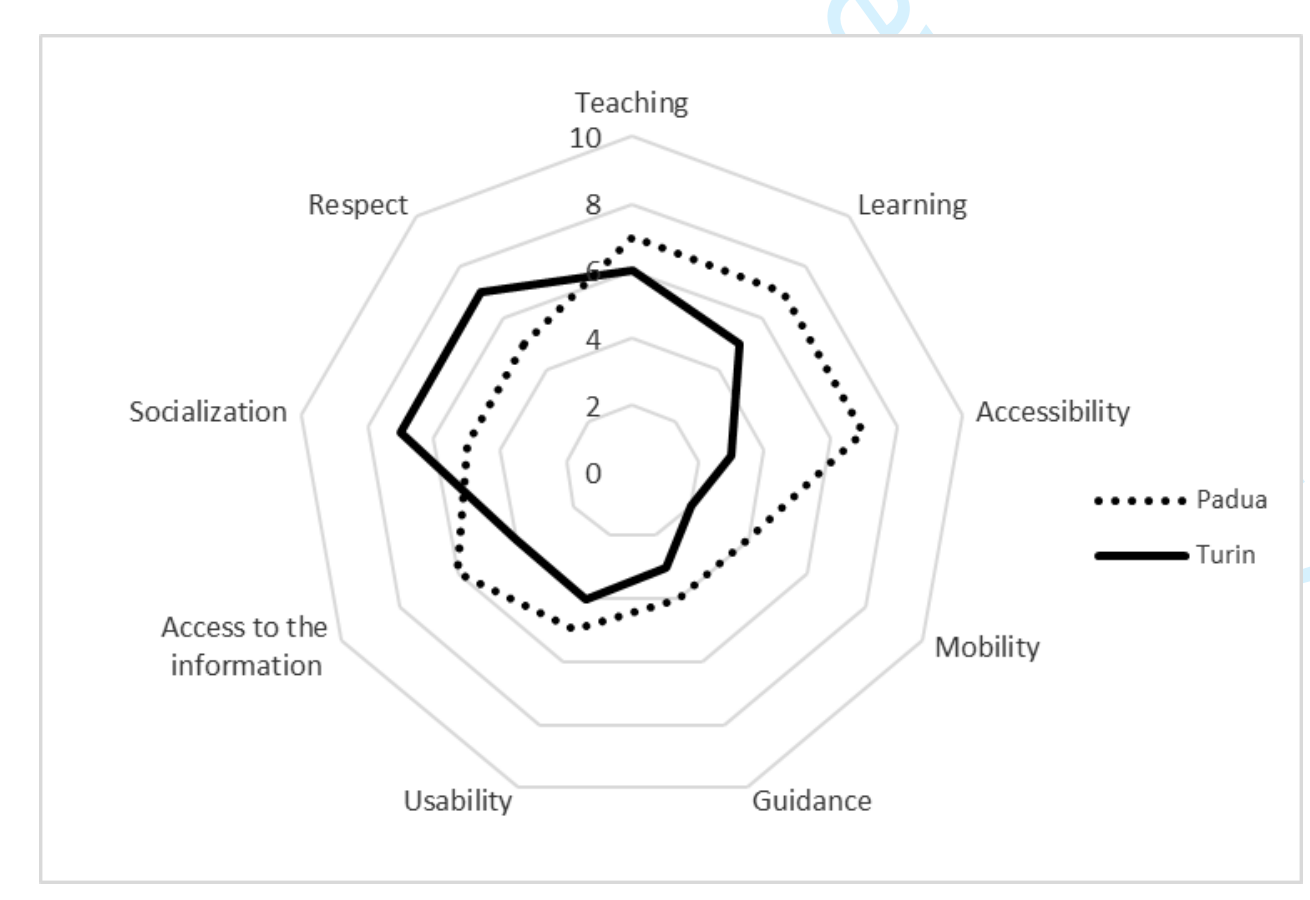


Table 1 Simplified SFGD Matrix

\begin{tabular}{llll}
\hline Ranking & $\begin{array}{l}\text { Opportunity level } \\
\text { (today) }\end{array}$ & $\begin{array}{l}\text { Assessment in terms of opportunity } \\
\text { level }\end{array}$ \\
\cline { 2 - 4 } & $\begin{array}{l}\text { How important is each } \\
\text { dimension? }\end{array}$ & $\begin{array}{l}\text { Which is the student } \\
\text { opportunity level today? }\end{array}$ & $\begin{array}{l}\text { How does the program/service support } \\
\text { the student opportunity level? }\end{array}$ \\
\hline Dimensions & & & \\
\hline
\end{tabular}

Table 2 SFGD Matrix designed with the students with disabilities

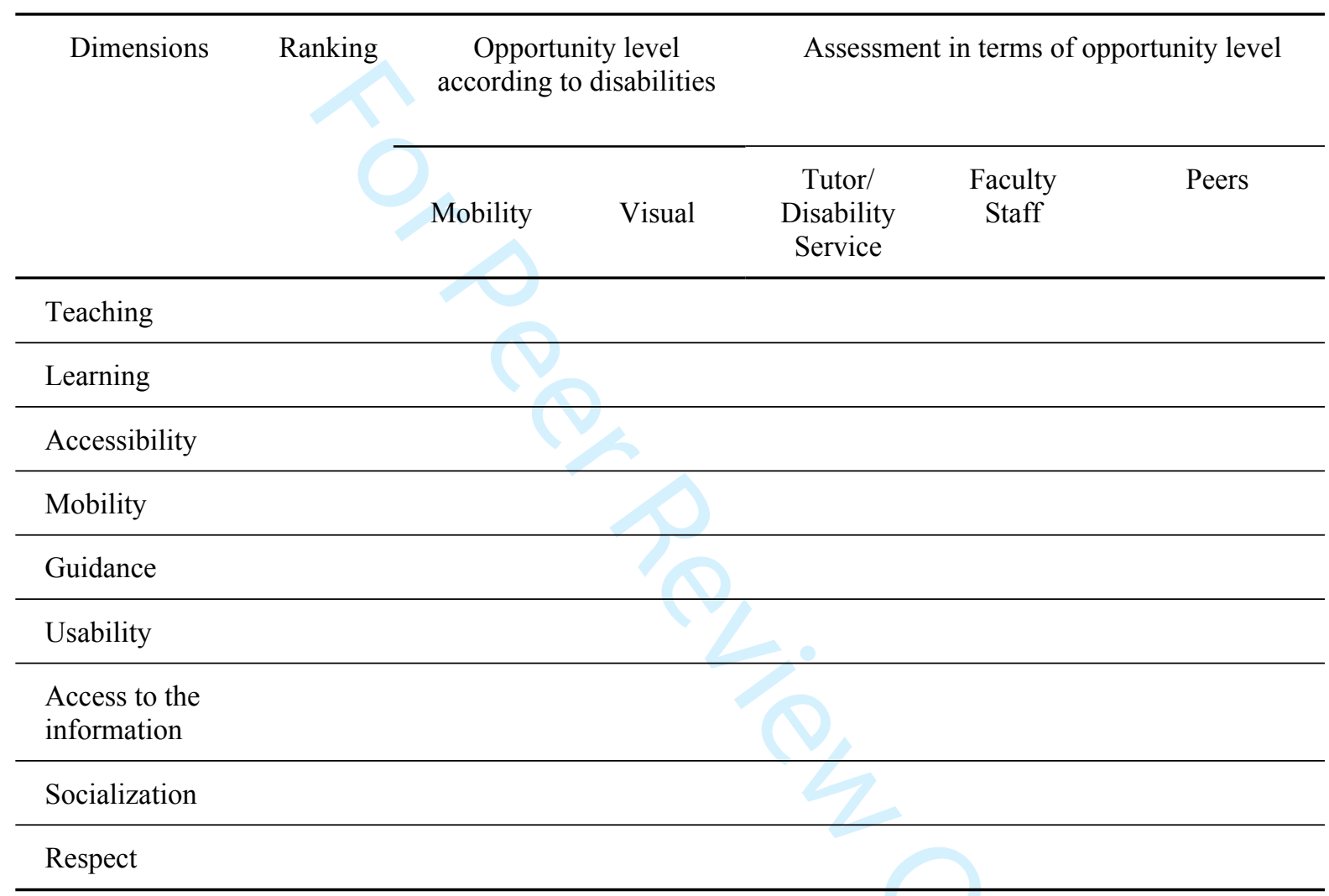

Table 3 Comparison

\begin{tabular}{ll}
\hline Scientific literature list & SWD list \\
\hline Teaching and learning & Teaching \\
Interior and exterior mobility & Learning \\
Interpersonal relationships and leisure time & Accessibility \\
Counselling and career development & Mobility \\
Access to information & Guidance \\
Respect & Usability \\
Well-being & Access to the information \\
Empowerment & Socialization \\
\end{tabular}

